
Laminates

March 1989

\author{
J. Schijve
}

th 
Crack stoppers and ARALL Laminates

J. Schijve 


\title{
CRACK STOPPERS AND ARALL LAMINATES
}

\author{
J. Schijve
}

Delft University of Technology, Faculty of Aerospace Engineering

\begin{abstract}
Tests were carried out on fatigue crack growth in 2024-T3 Alclad sheet specimens reinforced with strips. Strip materials were 2024-T3, 7075-T6, Ti-6Al$4 \mathrm{~V}$ and ARALL. Adhesive bonded and riveted strips were used. Integral strips were tested for 2024-T3 only. Several observations were made on crack growth retardation caused by the strips. Adhesive bonding gives better results than riveting. The best strip materials were ARALL and the Ti-alloy. ARATI advanced glass fibers are the most effective solution for crack stopper bands in a pressurized fuselage. Moreover they offer less production problems.
\end{abstract}

\section{INTRODUCTION}

Stringers in an aircraft structure can significantly reduce the growth rate of fatigue cracks. The residual strength properties are also depending on the structural configuration of skin and stringers. These aspects are well recognized in considerations on the damage tolerance of the aircraft structure. For the same purpose crack stopper bands, also labelled as tear strips, are applied in the aircraft fuselage to restrain the extent of fatigue cracking and to improve the residual strength if cracks are present. The weight of crack stopper bands is relatively low. In order to be effective and reliable, and to be cost-effective as well, a high fatigue resistance of the crack stopper bands is essential. For that reason ARALL crack stopper bands may well be a good choice. This question is the starting point of the present paper. To evaluate the problem some previous test programs carried out in our laboratory will be summarized. Three programs were planned as part of the master thesis work of Van Lipzig [1], Van Gestel [2] and De Kruijf [3]. The results of [1] and [2] were partly published before [4,5]. After reviewing the relevant information of the three programs, the application of crack stoppers in a pressurized fuselage will be discussed. Attention will be paid to ARALL as a crack stopper material. ARALL (ARamid ALuminium Laminates) is a hybrid material $[6,7]$, built up from thin aluminium alloy sheets $(0.3$ or 0.4 $\mathrm{mm}$ ), adhesively bonded to form a laminate with intermediate prepreg layers of unidirectionally aramid fibers embedded in a metal adhesive. ARALL was developed and patented as a new material with an exceptionally high resistance against fatigue crack growth. It can now be ordered from ALCOA. ARALL is a promising material for crack stopper bands in a fuselage, and this application is discussed in the present paper. 
SURVEY OF THREE TEST SERIES

\section{Scope:}

In three test series [1-5] specimens of 2024-T3 Alclad sheet material were provided with strips at either one side (test series 1 and 3 ) or at both sides (series 2). The cross sections and dimensions are shown in Figure 1, while Figure 2 shows a plan view of the specimen adopted in series 2. A similar lay out applies to series 1 . Specimens of series 3 are shown in Figure 3 . Information on the test variables is given in table 1.

The main purposes of test series 1 and 2 were:

1. To explore the restraint on fatigue crack growth by stiffening elements,

2. To compare the efficiency of bonded strips and integral strips.

For test series 3 the scope was broader:

3. To compare crack stopper bands of different materials and different ways of jointing the strips to the skin (see table 1). In view of the technical relevance of this test series the dimensions of the specimens were chosen to be larger than for the first two test series, see Figures 1 and 3 . In the third test series it was also tried to maintain the same stiffness of the strips for all materials involved. Although that goal was not fully achieved in view of available thicknesses, the stiffness ratios for the panels were approximately 0.25 . The stiffness ratio is defined as:

$$
\mu=\frac{\Sigma(E A)_{s t}}{(E A)_{s k i n}+\Sigma(E A)_{s t}}
$$

where $E=$ Young's modulus, $A=$ cross section and subscript $s t=$ stiffener.

\section{Specimen production:}

Adhesive bonding: The bonding was done with hot curing epoxies, see table 1 $\left(125^{\circ} \mathrm{C}\right.$ for FM123-5 and $120^{\circ} \mathrm{C}$ for FM-163-2). The usual Fokker procedures were followed, including pretreatments (chromic acid anodizing) and priming. For series 1 and 3 bonding was carried out by Fokker, for series 2 it was done in our own laboratory. The pretreatment of the Ti strips included degreasing, sandpapering and a one hour treatment in an activated peroxide bath. As a result of different thermal expansion coefficients the panels with Ti strips were curved after the bonding cycle, see Figure 3 . To a much lesser extent it also applies to the panels with ARALL strips. Under tensile loading the panels are easily straightened, but the initial curvature implies that 
residual stresses are present, which were calculated to be:

\begin{tabular}{lccr|} 
& $\alpha\left(10^{-6} /{ }^{\circ} \mathrm{C}\right)$ & $\mathrm{E}$ (MPa) & residual stress (MPa) \\
$2024-\mathrm{T3}$ (skin) & 23 & 71800 & +11 \\
ARALL (strips) & 17 & 68700 & +31 \\
Ti-6Al-4V (strips) & 9.5 & 117000 & \\
\end{tabular}

Integral strips: Integral strips were obtained by chemically milling material from a larger thickness. In test series 1 and 3 this occurred at one side only. The initial thickness was equal to the desired total thickness of skin and strips. As a consequence of the milling operation the cladding layer is removed. The surface quality of the chemically milled material is slightly different from the untreated material. It is expected to have no influence on fatigue crack growth, because the crack growth resistance of a material is a bulk property rather than a surface property. For test series 3 chemical milling was carried out by Fokker, for the other two test series is was done in our laboratory.

ARALL strips: Arall $7 \mathrm{H} 33$ is built up from 3 layers $7075-\mathrm{T} 6$, thickness $0.3 \mathrm{~mm}$, and 2 prepreg layers with 50 volume $z$ high modulus aramid fibers (Twaron from AKZO) in a matrix of AF-163-2 adhesive. The prepreg is made by the 3M company. After hot curing $\left(120^{\circ} \mathrm{C}\right.$ the material is post stretched to obtain residual tensile stress in the fibers and residual compression in the Al layers. This type of ARALL is now commercially available as ARALL-1 from ALCOA.

Riveting : Riveting was used in the third test series. The rivet diameter is $4 \mathrm{~mm}$, the rivet pitch is $20 \mathrm{~mm}$. For reasons of reproducibility an automatic hole drilling and riveting machine was used by Fokker.

\section{Experimental conditions}

All tests were carried out in lab air on computer controlled fatigue machines, with a capacity of $200 \mathrm{kN}$ (test series 1 and 2) and $1000 \mathrm{kN}$ (test series 3). The load frequency was in the order of $10 \mathrm{~Hz}$ for the first two test series, and $5 \mathrm{~Hz}$ for the larger specimens of test series 3 .

In test series 1 the crack growth was measured with a binocular microscope (14x) and a photo-chemically etched line grating on the specimens. In test series 2 an automatic electro-potential-drop method was used. The same method was also adopted to follow the crack tip when it was hidden behind the strips. For this purpose a calibration of the potential drop/crack length 
relation was carried out first. The method was also applied to indicate crack initiation in the strip itself, because at that moment the small crack was still invisible due to the adhesive fillet, see Figure 4. When the crack was growing in the strips and the skin simultaneously, visual crack growth observations were also made, because the crack front initially is not a straight line perpendicular to the sheet.

In the third test series the crack growth observations were again made by visual observations along a line grating system on the specimen surface. In this test series crack length values were relatively large.

\section{Evaluation of the test results}

\section{Test series 1 and 2}

Fatigue crack growth lives of test series 1 and 2 [1,2] are presented in Figure 5. Apart from an evident stress level effect, the figure shows two trends :

(1) In test series 1 the effect of the strips on fatigue life is relatively small. In test series 2 the effect is large. This might be expected because the thickness of the strips was much larger (see Fig.1), as illustrated by the higher stiffness ratio.

(2) The bonded strips lead to longer lives than the integral strips. This is not so evident in test series 1 with the low stiffness ratio, but it is quite obvious in test series 2. To elucidate this question further an example of crack growth curves is given in Figure 6 . Both types of strips lead to slower crack growth. In the first part of the crack growth life the crack tips have not yet reached the strip edges. In that period the slightly faster crack growth for the bonded strips can be due to two reasons. The crack is growing in clad material, whereas for the integral strips the crack grows in bare material. It was shown experimentally [8] that crack growth is faster in clad material, because the cladding layers hardly contribute to crack growth resistance. Secondly, when the crack is approaching the bonded strips, these strips have a lower restraining effect on crack opening because of the low shear stiffness of the adhesive bond line. The reduction on the stress intensity factor and the growth rate is less effective. The difference is also shown by Figure 7, where the crack growth rate da/dN is shown as a function of the crack length. However, after the crack tip has passed the edge of the strip the situation is reversed. Now the crack tip can grow immediately into 
the integral strip. The crack growth rate rapidly increases and total failure is imminent. This does not occur with the bonded strips. The crack will grow further in the sheet, but crack opening will become increasingly restrained by the strips, which initially are still fully intact. Only at a later stage crack nuclei will start in the strips (see Figure 6). As a consequence the initial growth in the strips is lagging behind the main crack in the sheet (Fig.4). The same crack growth delaying mechanism was observed for part through surface cracks in laminated sheet material $[2,5]$.

As long as the crack has not yet reached the strips a comparison between the test results and predictions can be made. This is done in Figure 8 . Experimental $\mathrm{K}$ factors for specimens with strips were derived from the crack growth rates. For this purpose the $\mathrm{da} / \mathrm{dN}-\delta \mathrm{K}$ relations from the unreinforced sheet material (bare for the specimens with integral strips and clad for the specimens with bonded strips) were used as a calibration curve. This leads to the geometry factor :

$$
C=\frac{K_{\text {experimental }}}{\sigma \sqrt{\pi a}}
$$

which is labelled by Vlieger and Broek [9] as the tip stress reduction factor, because:

$$
\mathrm{C}=\frac{\mathrm{K}_{\text {stiffened }}}{\mathrm{K}_{\text {unstiffened }}}
$$

The experimental results are compared to a predicted curve of Isida [10]. He made calculations for a sheet with line stiffeners along the edges for several values of the tensile stiffness and the in-plane bending stiffness of the line stiffeners. For the present application the line stiffeners were located at the inner edges of the strips $(x=40 \mathrm{~mm})$. The tensile and bending stiffness were calculated for all material located outside the inner edges $(x>40$ $\mathrm{mm}$ ). The predicted curve in Figure 8 is in good agreement with the experimental results. Isida's prediction does not extend beyond $a / 40=0.9$.

For large a-values, when the crack has passed the inner edge of the strips, Figure 8 confirms that the tip stress reduction factor goes through a minimum. However, for the integral strips it rapidly increases as soon as the crack is penetrating into the integral strip. For the bonded strips the minimum of the tip stress reduction factor is lower and it occurs at a longer crack length, which makes the bonded strip much more effective. Now the rapid increase after the minimum is due to cracks starting in the bonded strips. 
From the previous arguments there is an important conclusion to be drawn: The superior behaviour of the bonded strips, as compared to the integral strips, is depending on the resistance against fatigue crack initiation and propagation of the strip material. This was the argument to study ARALL and Ti-6Al-4V strips in the third test series, ARALL because of the high resistance against crack growth and the $\mathrm{Ti}$ alloy in view of its resistance against crack initiation.

\section{Third test series}

The third test series [3] was more directly related to the application of crack stopper bands in a pressurized fuselage. For that reason $\mathrm{S}_{\max }$ was chosen to be $90 \mathrm{MPa}$ with $\mathrm{R}=0$. Hoop stress levels of some well-known aircraft are presented in table 3. Different materials and jointing techniques were considered, see table 1 . Most tests were carried out in duplicate. For the riveted specimens it was tried to have crack growth through the rivet holes in one specimen, and between the rivet holes in the other panel, see Figures $9 a$ and $b$. It was not always successful because cracks preferred to grow into a rivet hole.

The bar chart in Figure 10 shows the crack growth lives obtained. Although certain trends can be observed from this figure, it does not show anything about crack growth development. Crack growth curves give more information about the growth retardation as a result of the strips, see the examples in Figure 11. However, more detailed information is obtained from crack growth rate curves as shown in Figures 12 to 14.

Figure 10 suggests small or negligible effects of $2024-T 3$ strips. A better impression is obtained from Figure 12. All three strip-skin connections cause a slowing down of the crack growth in a similar way as shown in Fig. 6 for test series 2. The retardation is less effective because the stiffness ratio is lower than in test series 2. The panels have spent most of the life before the crack tip is nearing the strips. As a consequence the obvious retardations in Fig.12 have a limited effect on the total life in Fig.10. Figure 12 confirms that crack initiation in the integral strip starts immediately when the crack reaches the strip. It occurs systematically later in the adhesive bonded strips. The latter ones remain intact for some time after the crack has passed the outer edge of the strip. 
Crack growth retardation in the panels with riveted strips becomes evident at a still larger a-value. Moreover the reduction of the da/dN is smaller. The retardation is caused by a reduction of $\delta \mathrm{K}$, which is a consequence of the restraint on crack tip opening due to the strips. The restraint is lower for the riveted strips than for the adhesive bonded strips. Two reasons can be mentioned. First, the restraining forces of the riveted strips occur at the rivet holes $A$ and $B$ (Figs $9 a$ and $b$ ), i.e. at a higher $X$-value than $X$ for the inner edge of the strips. For the bonded strips such forces do occur already at the inner edge. Secondly, the restraining forces depend on the strip stiffness between the rivet holes, or between the edges of the delaminated area of the bonded strips. Obviously the bonded strip then is a more favourable configuration.

As far as the cracks were growing between the rivet holes (Fig.9b), the overall retardation was somewhat less effective as compared to the case with cracks growing into the holes. In the latter case crack growth is stopped for a while, because it takes some time before crack initiation at the other side of the hole continues the growth of the crack. On the other hand, if cracks grow between the holes, it might be hoped that the restraint on crack opening is more effective, because holes $A$ and $B$ are now at a smaller distance (20 instead of $40 \mathrm{~mm}$ ). That enhanced stiffness effect will be partly offset by more fastener flexibility because the rivet loads will be higher. Moreover, the higher rivet load will also lead to an earlier crack initiation in the strip itself, and to a faster crack growth in the strip. Anyhow, the tests showed for these panel configuration that the cracks growing into the holes gave a slightly better performance.

Figures 13 and 14 illustrate the effect of different types of strip material for riveted and bonded strips respectively. The figures also illustrate the significance of a high fatigue strength of the strip material. For the 2024-T3 Alclad strip the fatigue strength is significantly lower than for the $\mathrm{T} i$ and the ARALL strips. As a consequence fatigue cracks are initiated in the 2024-T3 strips (o in Figs 12 to 14), which is followed by strip failure shortly afterwards (o in Figs 12 to 14), and then rather soon by panel failure. This does not occur with the Ti and the ARALL strips. If strip failure does not occur, it should be expected that the crack growth retardation is primarily a function of the stiffness of the strips. That is confirmed by both Figures 13 and 14, where Ti strips and ARALL strips show a 
more or less similar effect on the crack growth rate.

Figure 13 shows that crack initiation does still occur in the $\mathrm{Ti}$ and ARALL strips, but at a fairly large crack length in the skin. Initiation starts at the rivet holes and for the Ti strips it leads to a rapid failure of the strips and to complete failure of the panel. In the ARALL strips crack growth was very limited. At the moment that the skin was completely severed, only minor damage had occurred to the ARALL strips. The strips alone were able to carry the maximum of the cyclic load, which induced a maximum stress of $356 \mathrm{MPa}$. That is far below the ultimate tensile strength of the ARALL material $\left(\sigma_{\mathrm{U}}=800 \mathrm{MPa}\right.$, table 2$)$.

Bonded Ti and ARALL strips are more effective crack growth stoppers than riveted strips, see Figure 10 and compare Figures 13 and 14 . In the bonded Ti strips crack initiation did not occur anymore, which should be associated with the absence of the rivet holes. The Ti strips could carry the maximum of the cyclic load when the skin was fully cracked. The stress in the strips then is $523 \mathrm{MPa}$, whereas the $\sigma_{U}=1067 \mathrm{MPa}$. In the ARALL strips crack initiation was still observed, but it was limited to one of the three Al layers of the ARALL strip. The Al layer adjacent to the bond with the skin was partly cracked. Nevertheless, the ARALL strips could still carry the maximum of the cyclic load after the skin had fully cracked.

It is indeed an important observation that the fatigue damage in the ARALL strip occurs in the outer Al layer only. This observation was also made in flight-simulation tests on ARALL panels with four $Z$ stiffeners, which simulated a Fokker F-27 tension skin joint [12]. In this realistic structural component, fatigue damage in the ARALL stiffeners at the so-called finger strips was limited to the outer Al layer only. The damage did hardly grow and an extremely long fatigue life at a relatively high stress level was obtained. The same experience was extensively confirmed in a test on an ARALL full scale wing panel tested by Fokker [13]. The wing panel and the flightsimulation loading were based on the F-27 conditions.

The outer A1 layer of the ARALL strip is most severely loaded if the adjacent skin material has cracked. It was expected that a worthwhile improvement could be obtained if the ARALL strip was bonded to the skin with prepreg NPE 9055 . It is the same prepreg used for the production of ARALL, i.e. an adhesive with unidirectional fibers. Two panels were made in this way. The crack rate results are shown in Figure 14 . In one panel crack initiation in the ARALL 
strips was prevented. In the other one it occurred when the skin was almost completely cracked. Fatigue testing of this panel was continued for 28000 additional cycles after the skin was completely cracked. The fatigue damage of the strips was still rather small, viz. two strips had a $9 \mathrm{~mm}$ crack in the outer Al layer of the strip.

Vlieger (National Aerospace Lab. NLR) developed two analytical methods for the calculation of $\mathrm{K}$-values of panels with riveted stiffeners (program ARREST [14]) and bonded stiffeners (program BOND [15]). ARREST includes effects of fastener flexibility, stiffener bending and stiffener plasticity. BOND can account for delamination areas and shear deformation of the adhesive bond line. Vlieger has made calculations for some panels of test series 3 . The results are shown in Figures 15 and 16. Experimental $\mathrm{K}$-values in these figures were derived from the da/dN values of the panels and the $\mathrm{da} / \mathrm{dN}-\delta \mathrm{K}$ calibration data obtained on the unreinforced sheet material. Qualitatively the calculations predict the empirical trends. It is noteworthy that crack growth between the holes is predicted to have a slightly lower $\mathrm{K}$-value when the crack is passing the stiffener, whereas the tests do not indicate this reduction. Insufficient data on delamination of the bonded strips were available for the calculations in Figure 16. Assumptions and interpolations were made for this purpose. The qualitative agreement is still considered to be satisfactory. At the same time the results of the two graphs emphasize, that accurate predictions require detailed information about stiffnesses, fastener flexibility, adhesive compliance, etc. There is an additional problem for predictions on bonded panels, because the debonding has to be predicted also. Predictions on debonding are generally considered to be a difficult issue. As a consequence empirical justification will be essential for some time to come, especially so for bonded strips.

\section{DISCUSSION}

Some results of the three test series will be summarized first.

1. If a fatigue crack grows towards a strip the growth is retarded. The retardation is quite limited as long as the crack tip is not fairly close to the edge of an integral strip or bonded strip, or to the center line of a riveted strip. However, when the crack is growing below a bonded or riveted strip, a significant reduction of the crack growth rate can occur. 
The reduction is large if the strips have a relatively high stiffness. For that reason the growth rate reduction in Figure 7 is larger than in Figures 12 to 14 . These trends are in perfect agreement with trends predicted by fracture mechanics calculations. This kind of information is not new, because it can be found in several previous publications [e.g. 14-19].

2. The integral strip has a beneficial effect on crack growth until the moment that the crack enters the strip itself. From then on the retardation rapidly disappears. The bonded strip shows a much better behaviour. The crack in the skin can not directly enter the strip. The adhesive bond line is a kind of a barrier. Reinitiation of a fatigue crack nucleus in the strip material has to occur. As long as that process is not too successful, crack tip opening in the skin is restrained and the crack driving force will be reduced (lower $\delta \mathrm{K}$ ). Also this effect is depending on the stiffness of the strips.

3. In order to be a succcessful crack stopper, a strip should have a high fatigue resistance. Bonded strips are better than riveted strips because of the absence of rivet holes. Moreover, the restraint on opening of the crack tip in the skin material is more effective, which gives a better reduction of $\delta \mathrm{K}$, compare Figures 13 and 14.

According to the present Damage Tolerance Requirements $[20,21]$ fatigue cracks in a pressurized fuselage should not lead to a dangerous situation. Ample time for crack detection should be available, and sufficient residual strength should be provided. The question to be discussed now is: Do crack stopper bands improve the damage tolerance of a pressurized fuselage?

Crack stopper bands can not be supposed to improve the crack initiation life of the structure. As pointed out before, the bands will also have a minor effect on the initial growth of the fatigue crack. A beneficial effect can be expected if the cracks are approaching the bands, and even more when the crack is growing under the bands. The better results were obtained for ARALL and Ti strips. Crack stopper bands of these materials will allow a much longer time for crack detection than Al-alloy strips.

It is noteworthy that the ARALL and the Ti strips in the third test series could still carry the maximum fatigue load when the skin was completely severed. In this respect the panels tested are not a realistic representation of a fuselage. The width is $380 \mathrm{~mm}$ only, and there are four strips, but the stress in the strips after skin failure was still below $50 \%$ of the ultimate stress of the strip material. There is an obvious indication in this type of 
information. The ultimate strength of the crack stopper bands becomes significant if the fatigue crack remains undetected. In this respect there is a difference between bonded and riveted bands. Rivet holes reduce the cross section, and in addition a blunt notch effect can be involved. For the $\mathrm{Ti}$ alloy not much is known about the blunt notch effect. The Ti-6Al-4V may be expected to behave similar to the Al-alloys, which implies that net section yield can be obtained or exceeded. ARALL with aramid fibers was shown to be somewhat blunt notch sensitive [12], due to the low failure strain of the aramid fibers. Recently a significant improvement has been obtained by developing ARALL with advanced glass fibers [12]. The ultimate stress of this type of ARALL does rank as high as $1100 \mathrm{MPa}$, which is about equal to $S_{u}$ of the Ti-alloy, but with an approximately two times lower specific gravity. The first results on the blunt notch properties of ARALL with glass fibers are promising, which is associated with the significantly higher failure strain of the glass fibers.

Several practical aspects are involved in the question of selecting the material of crack stopper bands. Aluminium alloys can not compete with ARALI or $\mathrm{Ti}-6 \mathrm{Al}-4 \mathrm{~V}$, because of the lower fatigue strength and residual strength. There are aspects in favour of ARALL crack stopper bands if compared to Tialloy bands. First, similarly good results can be obtained for a much lower weight. Second, if the bands are bonded, the dissimilarity between ARALL and Al-alloy skin material is hardly significant. However, for $T i$ bands the dissimilarity has to be considered in view of thermal expansion effects ("pillowing" of the fuselage) and the adhesive bonding pretreatment procedures. For ARALL and Al-sheets the thermal expansion coefficient difference is much smaller, and adhesive bonding procedures are similar to those normally applied to aluminium alloys. Another type of dissimilarity has to be considered if riveted crack stopper bands are used. If $T i$ bands are adopted, holes have to be drilled simultaneously through $\mathrm{Ti}$ and $\mathrm{Al}$, which is an awkward combination from the production point of view. ARALL with Al-sheet does not offer serious problems.

Crack stopper bands usually necessitate the occurrence of joggles in the longitudinal stiffeners. That is a design aspect, which can not be discussed in general terms, because there are more complicating factors, such as attachment of frames to the skin and circumferential joints. If joggles are necessary for crack stopper bands, a low thickness band should be used. In 
other words a wide band rather than a thick band should be preferred. Especially if adhesive bonded bands are used, a wide band is not a problem, on the contrary, a wider contact area with the skin will improve the efficiency of the crack stopper.

It is believed that crack stopper bands of ARALL with glass fibers are an efficient and cost-effective solution to meet damage tolerance requirements and to increase the safety of the pressurized fuselage. It is expected that they can easily be introduced in new aircraft design, but also in aircraft already in production, without significant problems. There is an ironical aspect involved in the recommendation to use ARALL crack stopper bands. A further improvement of the fatigue resistance of the fuselage is the application of ARALL as a skin material. Since large fatigue cracks are no longer expected then, crack stopper bands become superfluous. Design studies to apply ARALL as a skin material for the fuselage are now underway. There is still some time to go before this application is fully evaluated, including airworthiness certification problems. However, the more simple application of ARALL crack stopper bands seems within reach now. 
CONCLUSIONS

Three test series were carried out on fatigue crack growth in 2024-T3 Alclad sheet specimens, reinforced with different strips, strip materials and jointing techniques. The main purpose was to study the crack growth retardation effect caused by the strips. The following observations were made: 1. An integral strip gives some crack growth retardation, which rapidly vanishes after the crack has reached the first edge of the strip. Crack growth retardation does occur when the crack is growing under a riveted or an adhesive bonded strip. The bonded strip is much more effective than the riveted strip. The retardation is larger for a higher stiffness of the strip. A long lasting retardation is not obtained if fatigue cracks are nucleated in the strip itself. This occurred in 2024-T3 and 7075-T6 strips, for both riveted and bonded strips. It also occurred in Ti-6Al-4V riveted strips, but at a significantly later stage. It did not happen in bonded strips of that material. The absence of rivets is profitable. In ARALL strips some fatigue damage occurred in the outer aluminium alloy layer, but failure of the strips did not occur. Bonding of the ARALL strips with a prepreg (adhesive with aramid fibers) gave a further improvement.

2. Fracture mechanics predictions on the above effects do indicate the trends, but experimental verification is still essential. There are several interacting mechanisms, which are not easily modelled in a quantitatively accurate way.

3. With respect to crack stopper bands in pressurized fuselages, it is concluded that such bands should have a high fatigue resistance, as well as a high ultimate strength. Adhesive bonded ARALL crack stopper bands with advanced glass fibers are the most effective solution, and not only because of the excellent fatigue properties, the high ultimate strength and the low specific density of this new material. Ti-alloy crack stopper bands on an Alalloy skin lead to production problems in view of the dissimilarity of the two materials, which do not occur, or to a much lesser extent, in ARALL crack stoppers.

Acknowledgement: The participation of Harry van Lipzig, Berry van Gestel and Rob de Kruijf, who carried out the test series, the fracture mechanics calculations made by Henk Vlieger (NLR), and stimulating discussions with Boud Vogelesang and JanWillem Gunnink are much appreciated. AKzO, ALCOA and the 3M Company provided the materials, and Fokker carried out part of the chemical milling and the riveting. 


\section{REFERENCES}

1. van Lipzig,H.T.M.'The retardation of fatigue cracks' (in Dutch) Thesis Delft University of Technology (1973)

2. van Gestel,G.F.J.A.'Crack growth in laminate sheet material and in panels with bonded or integral stiffeners' (in Dutch) Thesis Delft University of Technology (1975)

3. de Kruijf, R.'ARALl as crack stopper material' Thesis Delft University of Technology (1985)

4. Schijve, J and van Lipzig, H.T.M.'Investigation on the fall safe properties of laminated sheet material' (in Dutch) Delft University of Technology, Report VTH-188 (1974)

5. Schijve,J., van IIpzig,H.T.M., van Gestel,G.F.J.A. and Hoeymakers,A.H.W. 'Fatigue properties adhesivebonded laminated sheet material of aluminum alloys' Eng.Fracture Mech. 12 (1979) pp 561-579

6. Vogelesang, L.B., Marissen,R and Schijve,J.'A new fatigue resistant material: Aramid Reinforced Aluminium Laminate (ARALI)' Proc. 11th ICAF Symposium, Noordwijkerhout (1981), paper 3.4, Nat.Aerospace Lab. NLR, The Netherlands

7. Vogelesang,L.B. and Gunnink,J.W.'ARALL: a materials challenge for the next generation of aircraft' Materials and Design $\underline{Z}$ (1986) pp 287-300

8. Schijve,J.,Jacobs,F.A. and Tromp,J."The significance of cladding for fatigue of aluminium alloys in aircraft structures' TR 76065 (National Aerospace Laboratory NLR, The Netherlands, 1976)

9. Vlieger.H and Broek, D, 'Built-up sheet structures. Wings' AGARDograph No.176 (1974) pp 195-225

10. Isida,M.,Results quoted in 'Stress intensity factors handbook' ed. by Y.Murakami, Pergamon Press (1987), Vol.1, pp 2228-231

11. Niu,M.C.'Airframe structural design' Conmilit Press (1988),p. 383

12. Vogelesang, L. B. , Gunnink, J.W. ,Chen, D. ,Roebroeks, G. H. J.J. and Vlot, A. 'New developments in ARALL Laminates' Proc. 16th ICAS Congress, Jeruzalem (1988)

13. van Vegge1, L.H., Jongebreur, A.A. and Gunnink, J.W.' Damage tolerance aspects of an experimental ARALL F27 lower wing skin panel' Proc.14th ICAF Symp., Ottawa (1987), EMAS, pp

14. Vlieger,H. and Sanderse,A.'User's manual of ARREST, a computer routine to predict the residual strength of cracked panels with riveted stiffeners' TR 84134 (Nat. Aerospace Lab.NLR. The Netherlands, 1984)

15. Vlieger,H.'Residual strength of bonded stiffened panels: prediction and experimental verification' TR 83066 (Nat.aerospace Lab.NLR, The Netherlands, 1983)

16. Smith,S.H.,Porter, T.R. and Engstrom,W.L.'Fatigue crack propagation behavior and residual strength of bonded strap reinforced, lamellated and sandwich penels' Proc.Air Force Conf. 'Fatigue and Fracture of Aircraft Structures and Materials'(1969), AFFDL TR 70-144,pp 611-634

17. Swift, T'The effects of stress level, geonetry, and material on fatigue damage tolerance of pressurized fuselage structure' Proc.14th ICAF Symp., Ottawa (1987), EMAS, pp 1-77

18. Liebowitz,H.(ed.)'Fracture Mechanics of Aircraft Structures' AGARDograph No.176 (1974)

19. Liebowitz,B.(ed.)'Practical Applications of Fracture Mechanics' AGARDograph No.257 (1980)

20.'Damage Tolerance and Fatigue-Evaluation of Structure' Draft Advisory of Circular, AC No.25.571-1A, US Department of Transportation, FAA (1985)

21. 'Damage Tolerance and Fatigue Evaluation of Structure (Acceptable Means of Compliance)' JAR 25, Ch.7, Amend.7, 24 Nov 1980, ACJ 25.571(a) 


\begin{tabular}{|c|c|c|c|c|c|}
\hline $\begin{array}{c}\text { Test } \\
\text { series }\end{array}$ & $\begin{array}{c}\text { Fatigue } \\
\text { Smax } \\
\text { (MPa) }\end{array}$ & $\begin{array}{l}\text { load } \\
\qquad \mathrm{R}\end{array}$ & Materials & $\begin{array}{l}\text { strip } \\
\text { skin } \\
\text { joint }\end{array}$ & adhesive \\
\hline 1 & $\begin{array}{r}147.2 \\
117.7 \\
88.3\end{array}$ & 0.33 & 2024-T3 Alclad & $\begin{array}{c}\text { bonded } \\
\text { integral }\end{array}$ & FM123-5 \\
\hline 2 & $\begin{array}{r}117.7 \\
88.3\end{array}$ & 0.33 & 2024-T3 Alclad & $\begin{array}{c}\text { bonded } \\
\text { integral }\end{array}$ & FM123-5 \\
\hline 3 & 90 & 0.035 & $\begin{array}{cc}\text { skin: } & 2024-\mathrm{T} 3 \text { Alclad } \\
\text { strips }: & 2024-\mathrm{T} 3 \text { Alclad } \\
& 7075-\mathrm{T} 6 \mathrm{Clad} \\
\text { Ti-6Al-4V } \\
\text { ARALL } 7 \mathrm{H} 33 \\
\text { (0.48 prestrain) }\end{array}$ & $\begin{array}{c}\text { riveted } \\
\text { bonded } \\
\text { integral } \\
(*)\end{array}$ & $A F-163-2$ \\
\hline
\end{tabular}

Table 1: Variables of test series 1,2 and 3 .

(*) integral $2024-\mathrm{T} 3$ only

\begin{tabular}{|c|l|c|rrr|}
\hline $\begin{array}{c}\text { Test } \\
\text { series }\end{array}$ & Material & $\begin{array}{c}t \\
(\mathrm{~mm})\end{array}$ & $\sigma_{0.2} \begin{array}{c}\sigma_{\mathrm{U}} \\
(\mathrm{MPa})\end{array}$ & $\begin{array}{c}\delta \\
(8)\end{array}$ \\
\hline 1 & $2024-\mathrm{T} 3$ Alclad & 1 & 340 & 452 & 24 \\
& & 2 & 348 & 454 & 22 \\
\hline \multirow{2}{*}{2} & $2024-\mathrm{T} 3$ Alclad & 1 & 336 & 451 & 14 \\
& & 2 & 349 & 469 & 14 \\
& & 5 & 361 & 463 & 16 \\
\hline \multirow{2}{*}{3} & $2024-\mathrm{T} 3$ Alclad & 1.26 & 365 & 495 & 15 \\
& 7075-T6 Clad & 1.19 & 473 & 529 & 8 \\
& Ti-6Al-4V (annealed) & 0.83 & 1026 & 1067 & 8 \\
& ARALL 7H33 & 1.35 & 660 & 800 & 2 \\
& (0.48 prestrain) & & & & \\
\hline
\end{tabular}

Table 2: Material properties.

\begin{tabular}{|c|c|}
\hline aircraft type & $\begin{array}{l}\text { nominal hoop } \\
\text { stress (MPa) }\end{array}$ \\
\hline Lockheed L-1011 & 97 \\
\hline Boeing 707 & 88 \\
\hline Boeing 747 & 112 \\
\hline Douglas DC- 8 & 89 \\
\hline Douglas DC-9 & 90 \\
\hline Douglas DC-10 & 103 \\
\hline Fokker 100 & 82.5 (*) \\
\hline
\end{tabular}

Table 3: Hoop stress levels in pressurized fuselages after Niu [11] 


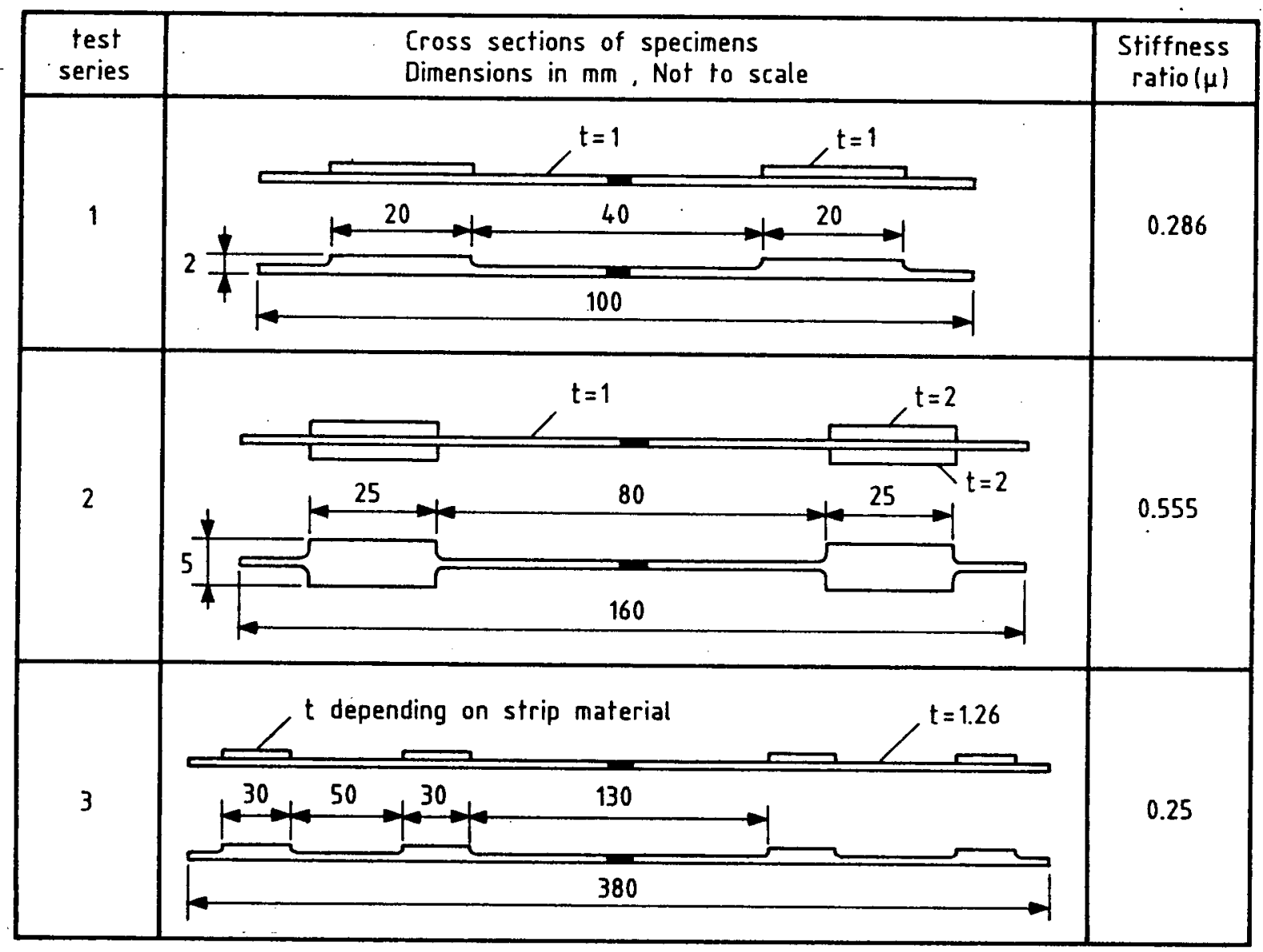

Figure 1 : Cross sections of the fatigue crack growth specimens used in test series 1,2 and 3 .

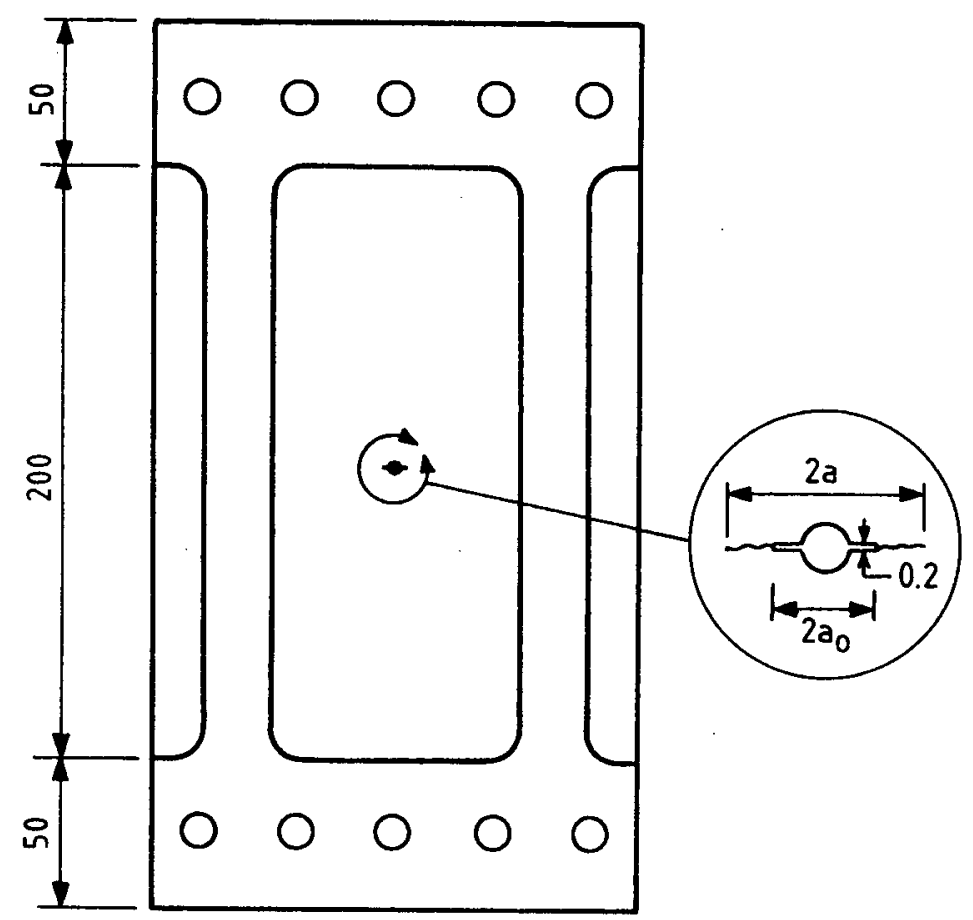

crack starter notch, hole $(1 \mathrm{~mm})$ with two saw cuts.

$2 \mathrm{a}_{0}=3 \mathrm{~mm}$ (series 1.2$)$

$2 a_{0}=4 \mathrm{~mm}$ (series 3 )

Figure 2: Lay out of specimen of series 2. 


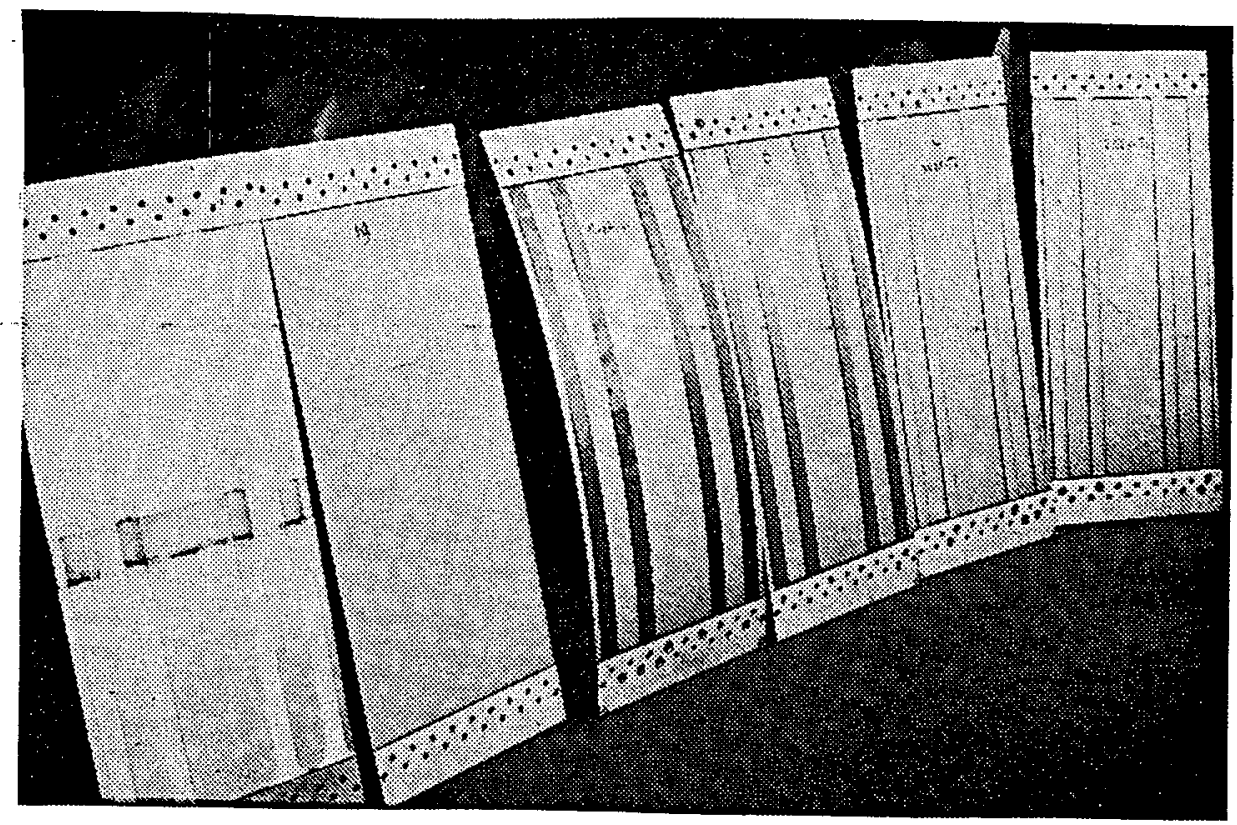

Figure 3: Test panels from test series 3 . Length of panels $940 \mathrm{~mm}$. Configuration of crack stopper bands, from left to right integral, unstiffened, bonded Ti, ARALL, 7075-T6 clad, 2024 - T3 Alclad.
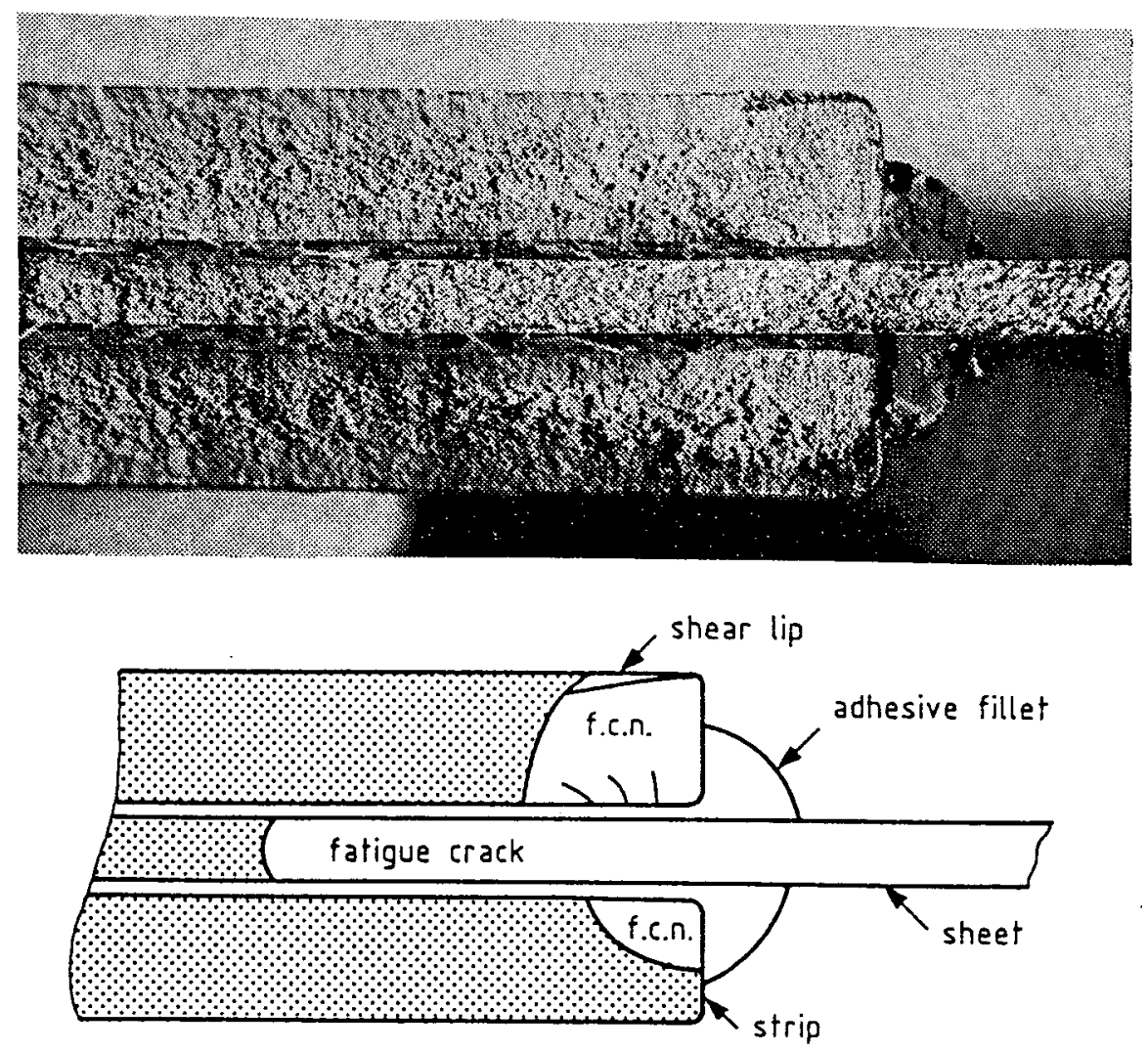

f.c.n. = fatigue crack nucleus in strips

Figure 4: Fracture surface after residual strength tests. Hidden crack in sheet has grown further than cracks in the strips. 


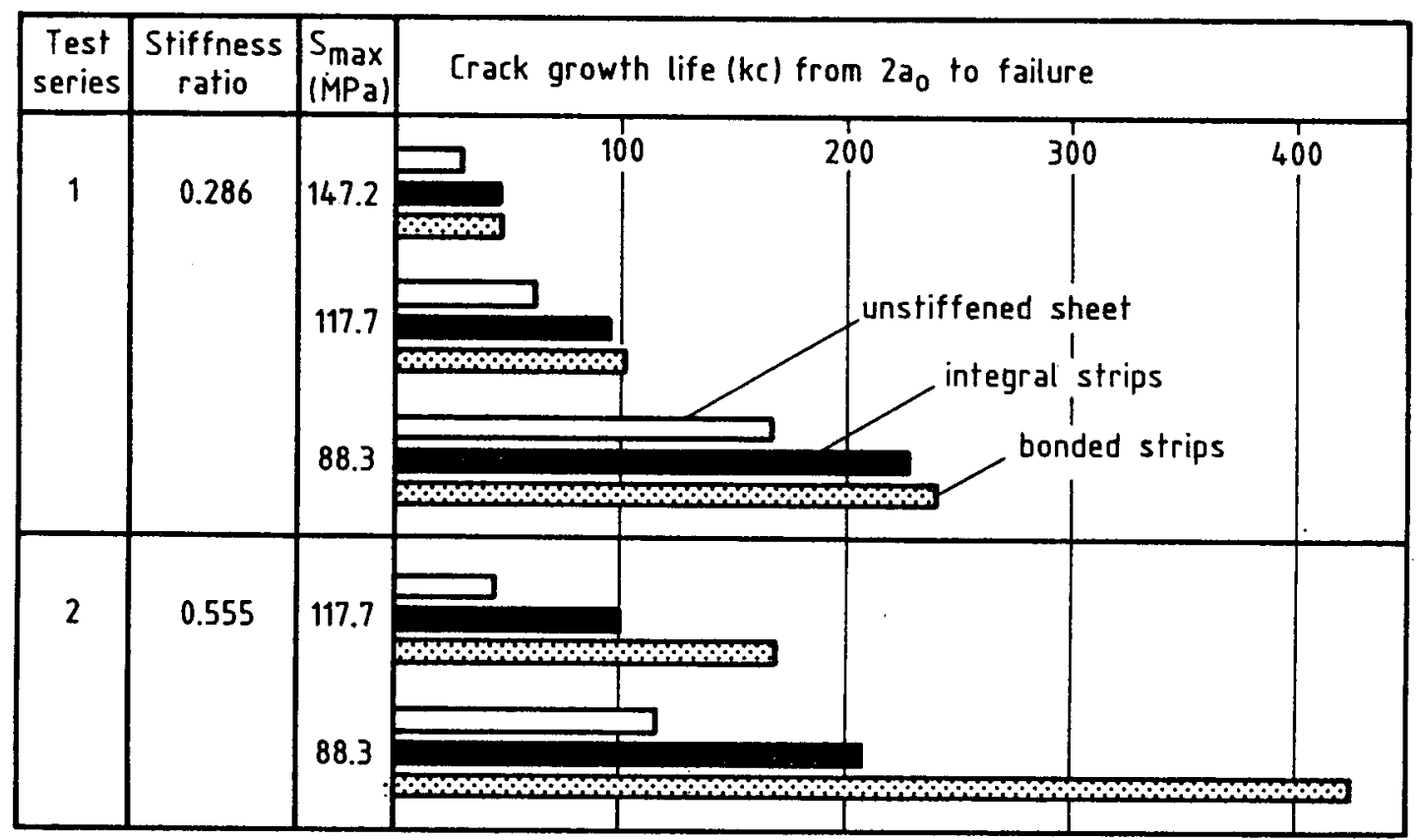

Figure 5 : Effects of integral strips and bonded strips on fatigue crack growth life. $\left(2 a_{0}=6 \mathrm{~mm}\right.$ for test series $1,2 a_{0}=10 \mathrm{~mm}$ for test series 2$)$

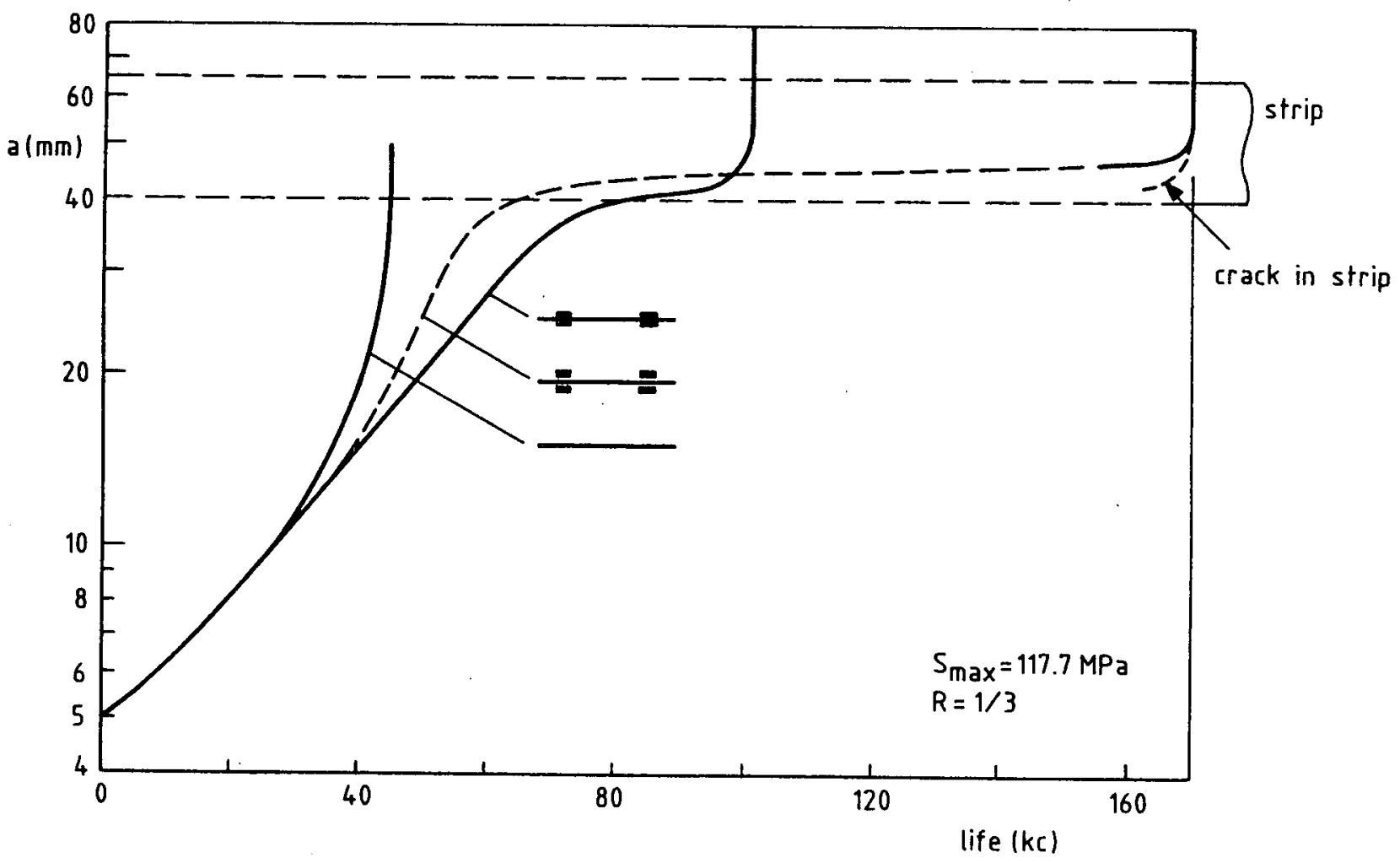

Figure 6 : Different crack growth behaviour for bonded and integral strips. (test series 2) 


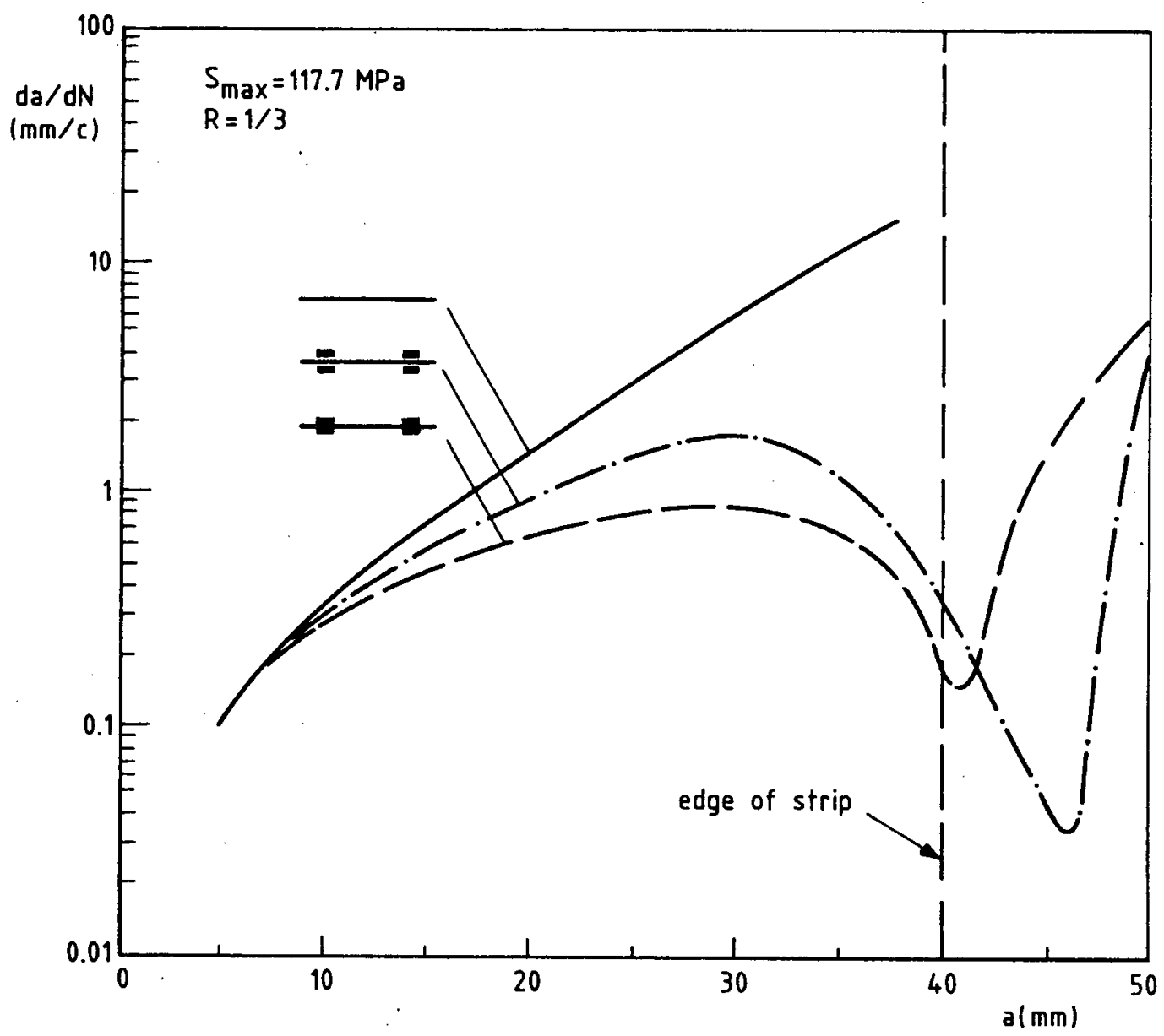

Figure 7: The crack growth rates corresponding to Figure 6 .

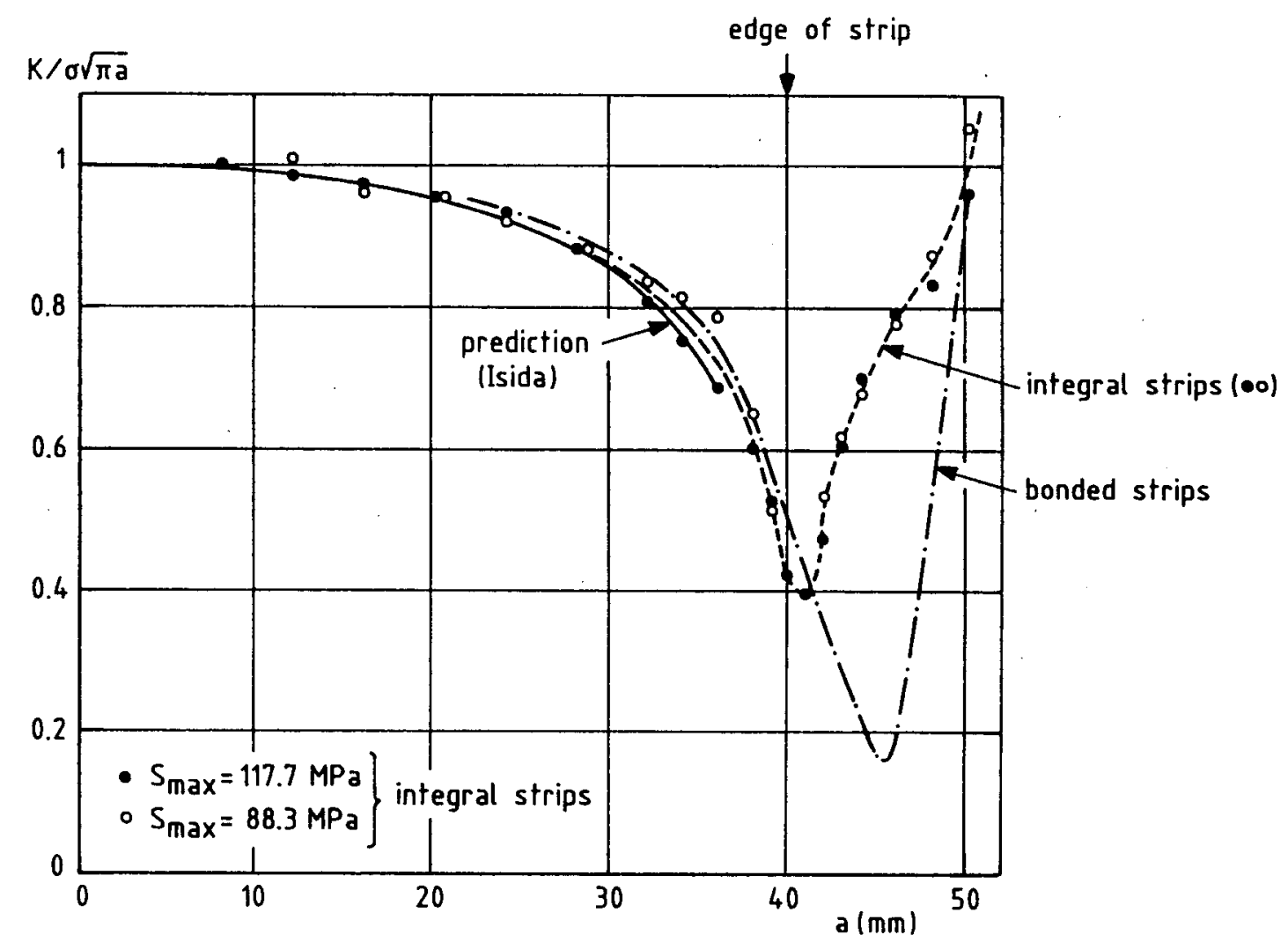

Figure 8 : The experimental tip stress reduction factor obtained in test series 2. Comparison to prediction by Isida [10]. 


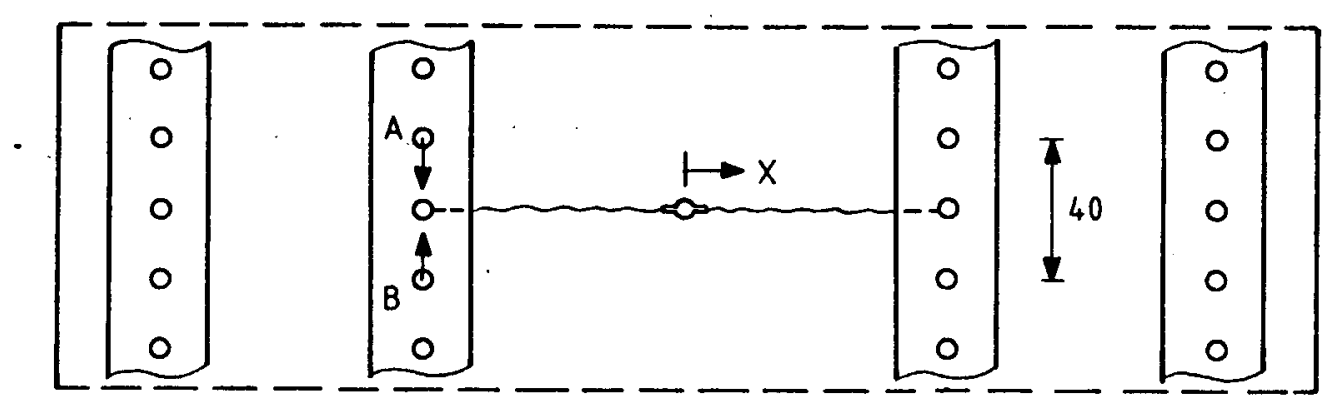

Fig. 9a: Crack. grows into rivet holes

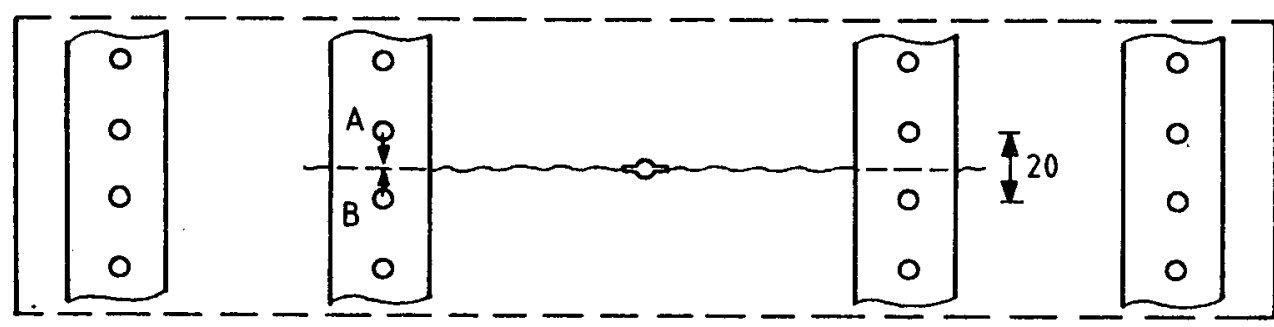

Fig. $9 b$ : Crack grows between rivet holes

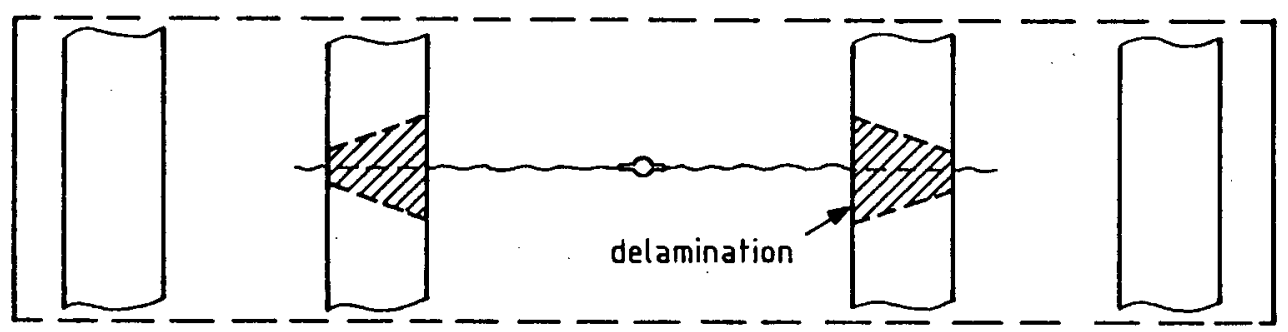

Fig. $9 c:$ Bonded strips Delaminated areas

Figure 9: Three different crack growth situations (test series 3).

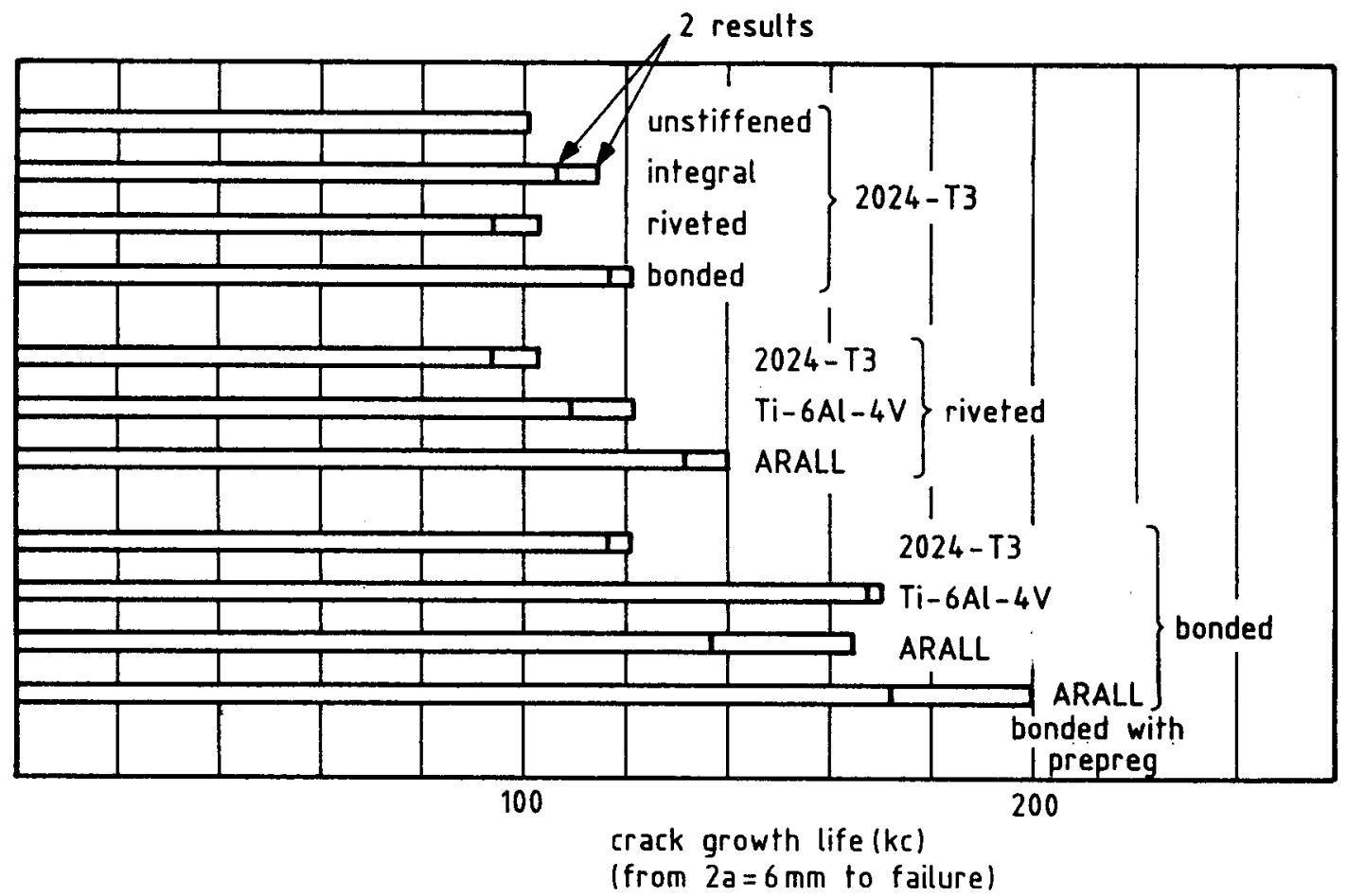

Figure 10: Effects of different strip materials and strip-skin jointing techniques on fatigue crack growth life (from $2 a_{0}=6 \mathrm{~mm}$ to failurel.Test series 3 . 


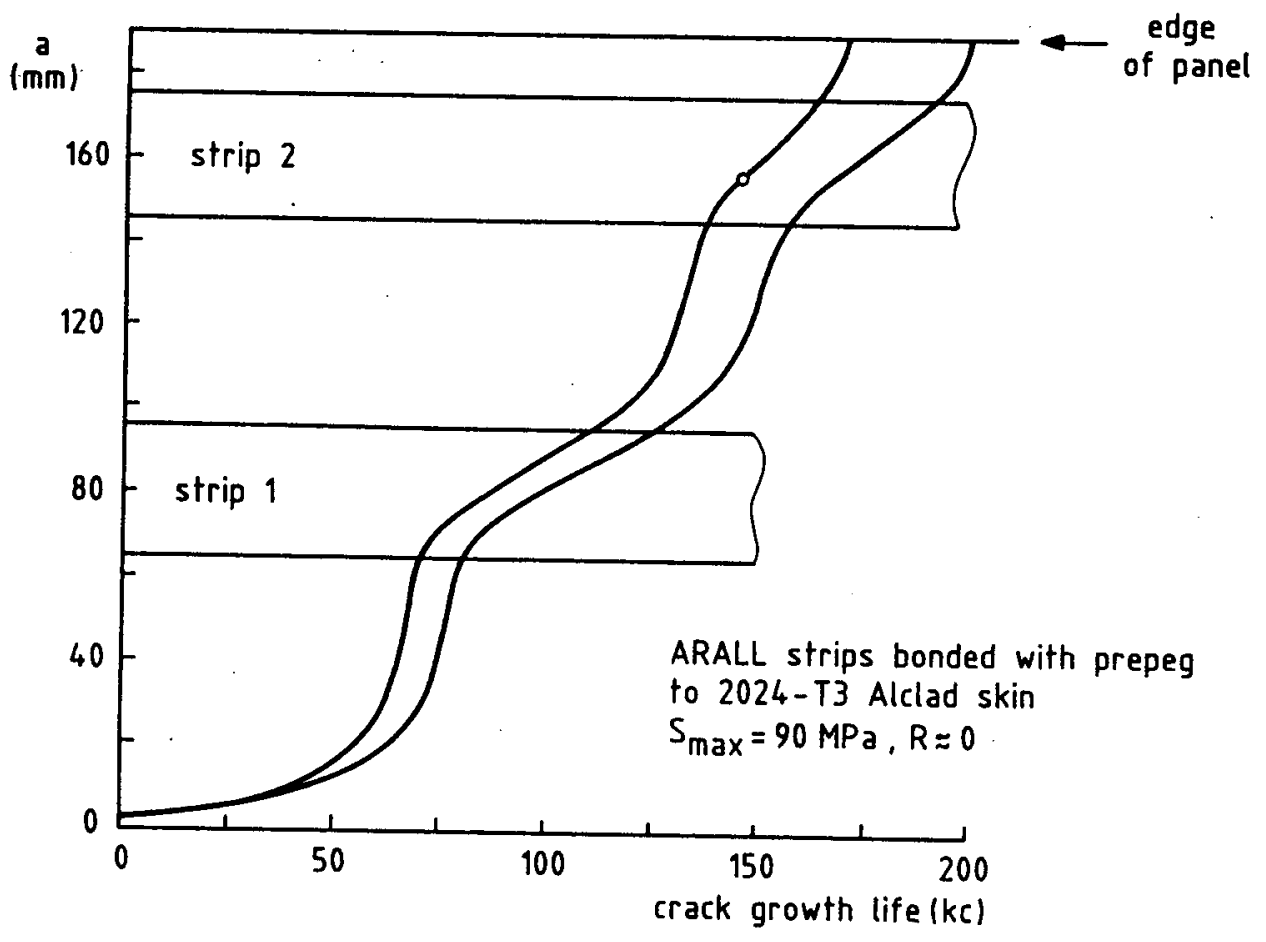

Figure 11: Crack growth curves of 2 panels of test series 3.

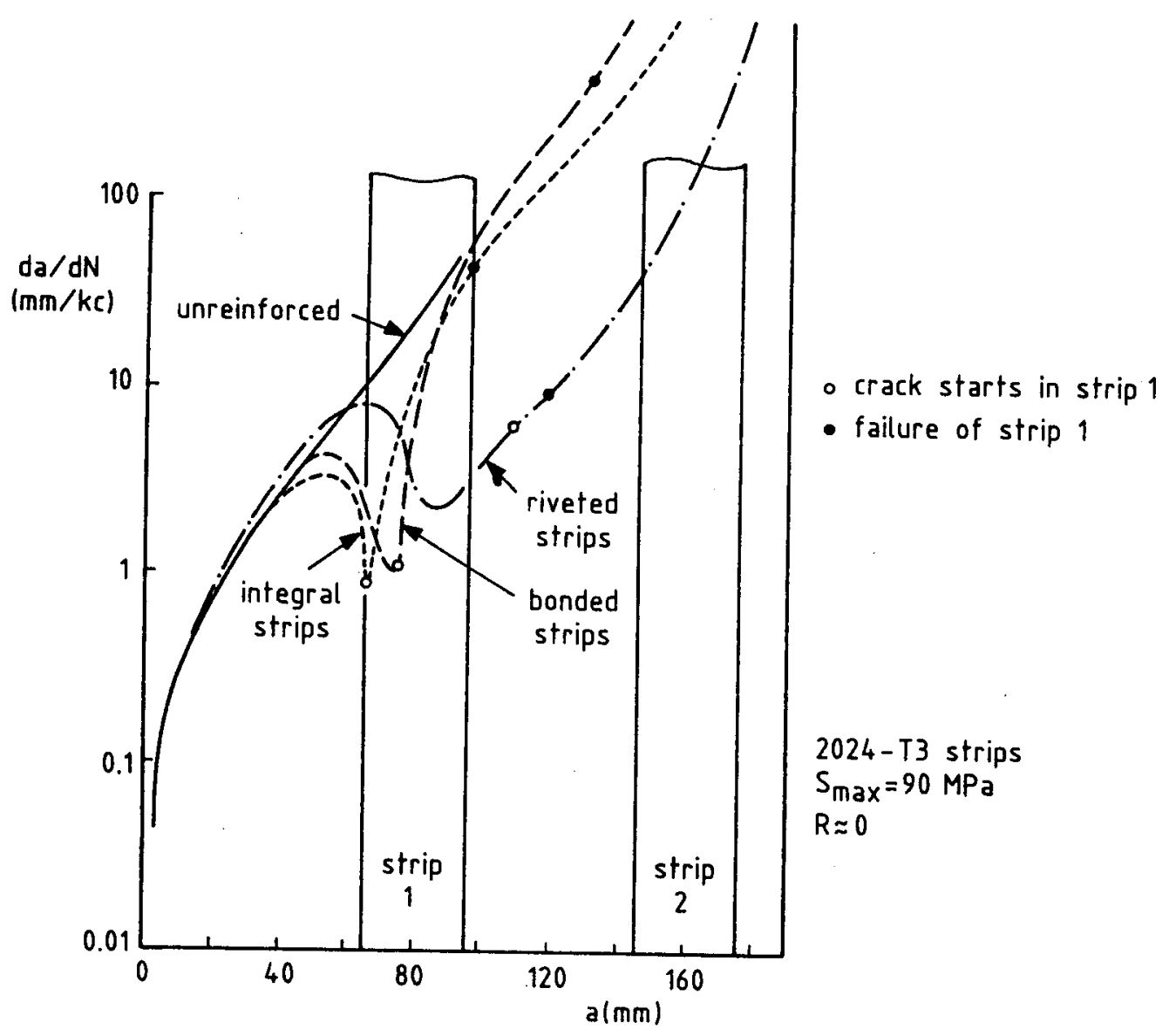

Figure 12: The effects of different strip-skin jointing techniques on the crack growth rate. 


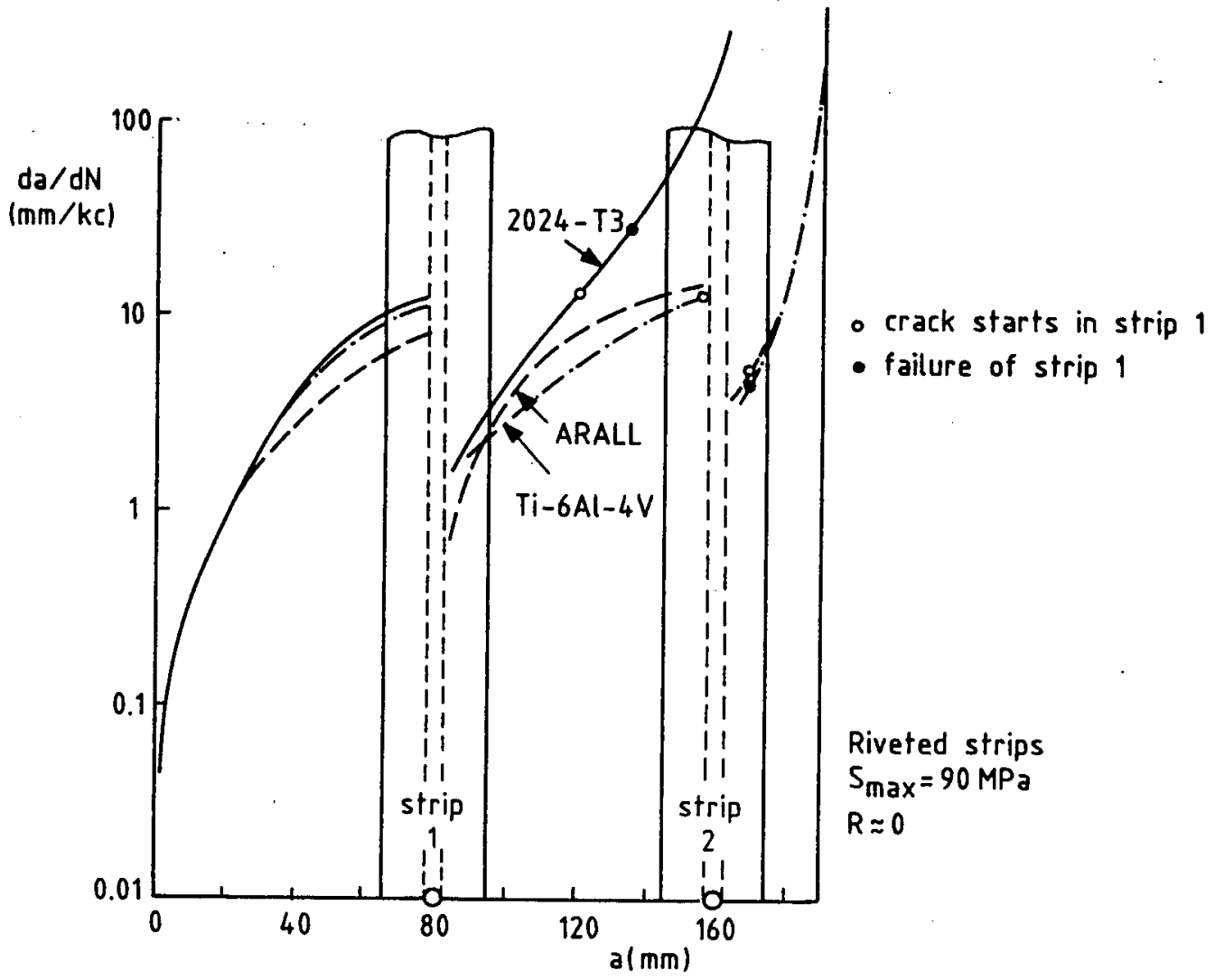

Figure 13: Effect of different strip materials on the crack growth rate. Riveted strips, crack growth through the holes, test series 3.

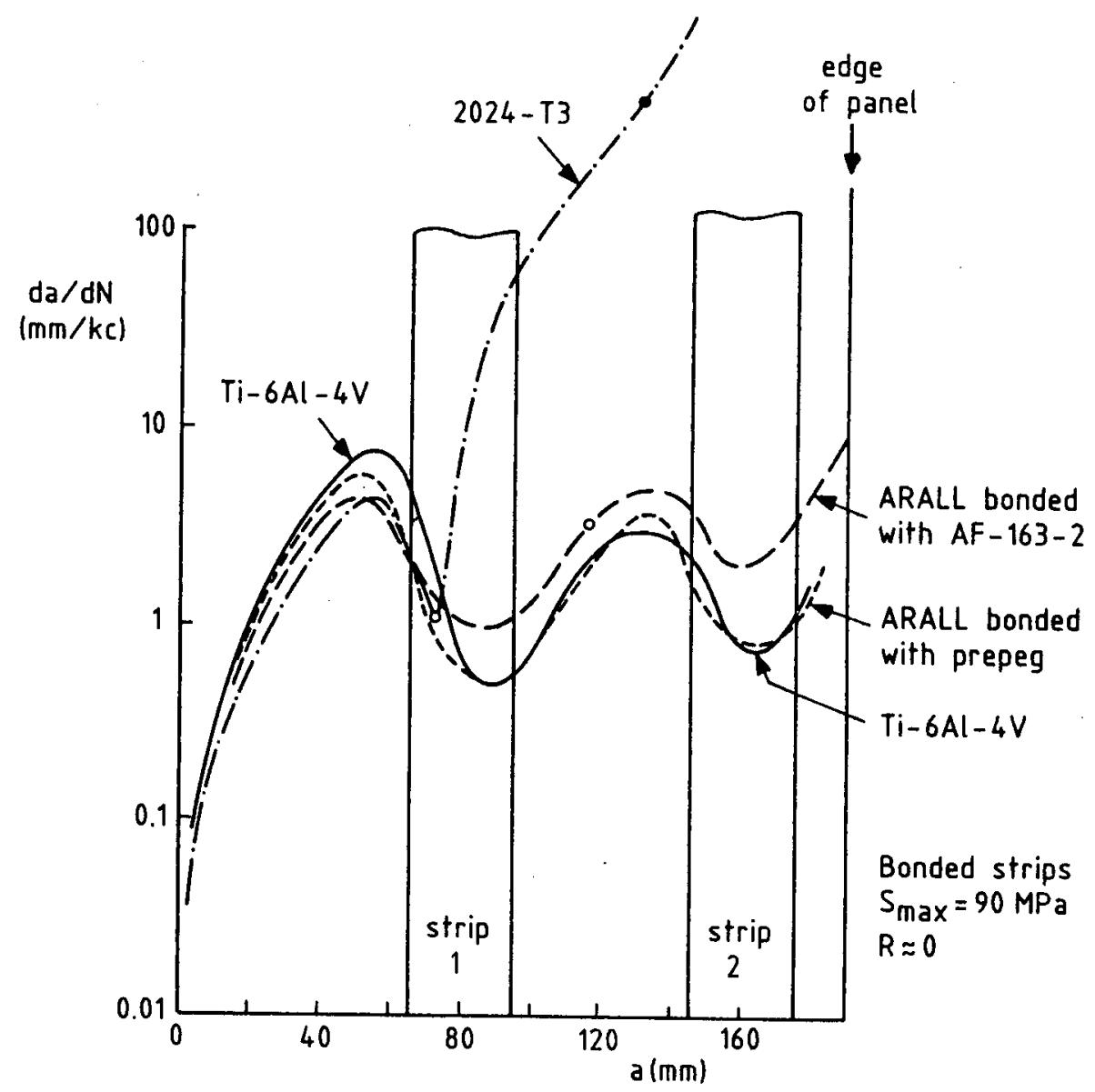

Figure 14: Effect of different strip materials on the crack growth rate. Bonded strips, test series 3 . 

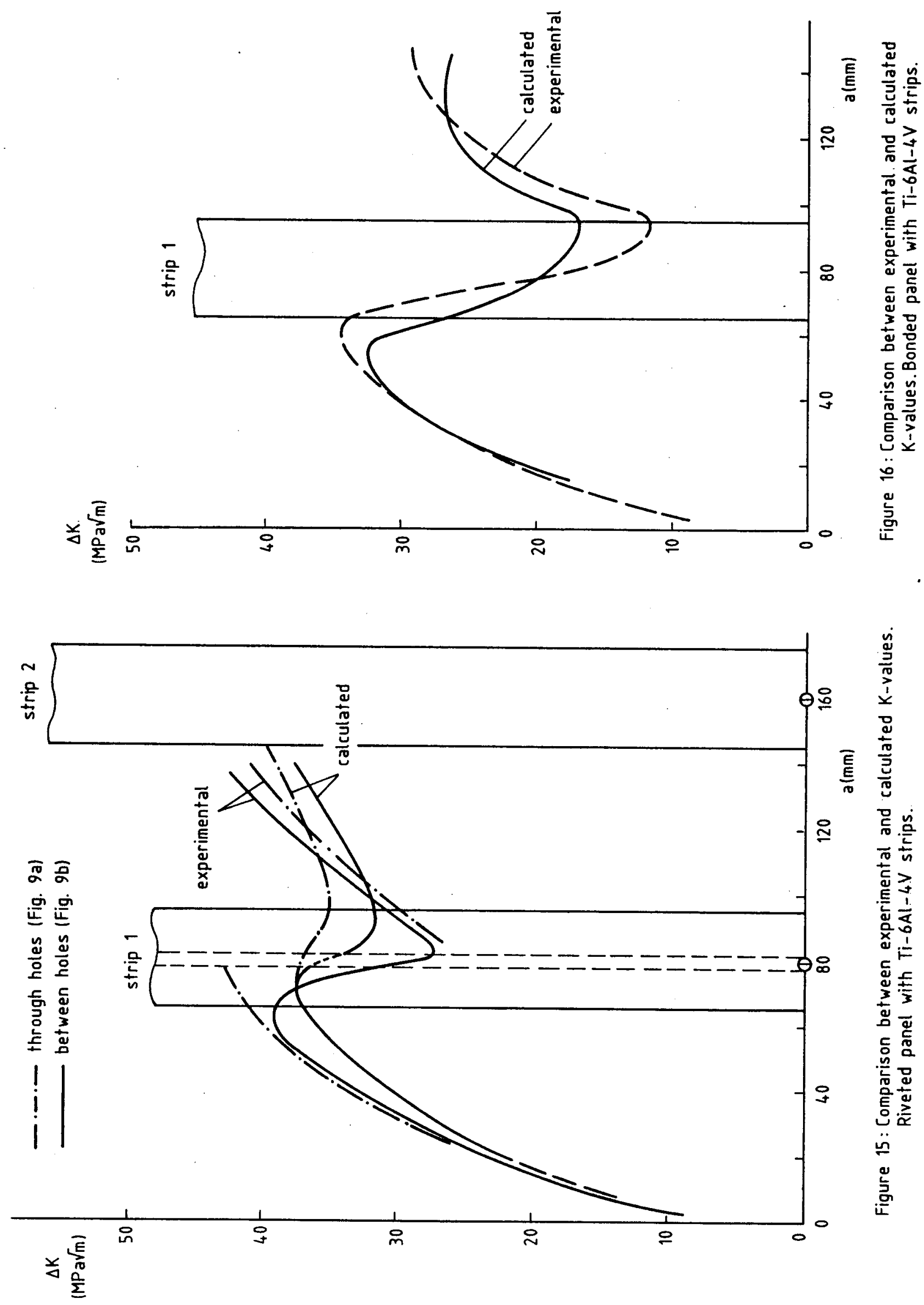


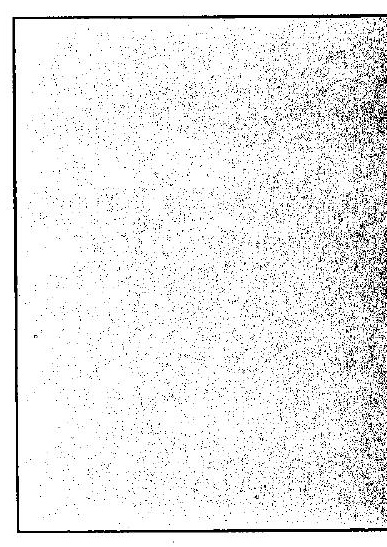

802044 